Volume 16 - Número 1 - jan/jul de 2021

\title{
ESTUDO VARIACIONISTA DA REDUÇÃO DA PREPOSIÇÃO PARA EM MACEIÓ/AL
}

\section{VARIATIONISTIC STUDY OF THE REDUCTION OF PREPOSITION PARA IN MACEIÓ/AL}

\author{
René Alain Santana de Almeida ${ }^{1}$ \\ Alan Jardel de Oliveira ${ }^{2}$
}

\begin{abstract}
RESUMO: Este artigo objetiva observar de que forma se processa a variação da preposição para em suas variantes [para], [pra] e [pa], no falar de Maceió, em função da influência de fatores sociais e linguísticos. Nesta pesquisa, o corpus foi coletado com trinta informantes. Foram testadas as seguintes variáveis independentes: contexto fonológico seguinte, paralelismo, acento da sílaba seguinte, classe da palavra seguinte, presença de tepe no item seguinte, faixa etária e sexo. As gravações coletadas foram anotadas no ELAN e a análise multivariacional dos dados realizada com o programa Goldvarb, que não considerou como estatisticamente significativa a interferência das variáveis paralelismo e classe morfológica da palavra seguinte na variação estudada. Do corpus coletado, verificamos um número inexpressivo (menos de 1\%) de ocorrências da variante para. Os contextos favoráveis à forma inovadora $p a$ foram: i) as consoantes coronais e as vogais posteriores; ii) a presença de tepe na sílaba seguinte; e iii) a ausência de acento na sílaba seguinte. Além disso, constatamos que os mais jovens e as mulheres produzem mais a variante [pra]. Esses resultados apontam para o desaparecimento da variante [para] na fala dos maceioenses.
\end{abstract}

PALAVRAS-CHAVE: Sociolinguística variacionista. Falar alagoano. Redução na preposição para.

ABSTRACT: This paper aims to analyze how the variation of the preposition para to its variants [para], [pra] and [pa], in speech from Maceio, is processed due to the influence of social and linguistic factors. In this research, the corpus was collected with thirty informants. We tested the following independent variables: next phonological context, parallelism, accent of the next syllable, class of the next word, presence of tepe in the following item, age-grading and sex. The collected recordings have been transcribed in the ELAN and multivariate analysis of the data has been performed by Goldvarb, program which did not consider the interference of the variables parallelism and morphological class of the following word as statistically significant in the studied variation. From the collected corpus, we verified an low amount (less than 1\%) of occurrences of the variant [para] which it was removed from the analysis. So, the favorable contexts for innovative form [pa] were: i) coronal consonants and back vowels; ii) presence of tepe in next syllable; and iii) absence of accent on the next syllable. In addition, we found that younger and women speakers produce the variant [pra]. These results point to the disappearance of the variant [para] in maceioense's speech.

KEYWORDS: Variationist sociolinguistics. Speech of Alagoas. Reduction in preposition para.

\section{Introdução}

Durante a primeira metade do século XX, o modelo teórico predominante de estudo da língua era o estruturalismo, que, devido ao contexto positivista em que se desenvolveu, considera a língua, enquanto objeto de estudo, como homogênea e abstrata, enquanto a fala seria assistemática por ser heterogênea. Na segunda metade do mesmo século, quando a Linguística já havia se adequado aos requisitos cientificistas do Positivismo, intensificaram-se pesquisas buscando sistematizar o uso concreto da língua considerando fatores externos a ela

\footnotetext{
${ }^{1}$ Doutor em Linguística pela Universidade Federal de Alagoas. Docente do Departamento de Letras Vernáculas da Universidade Federal de Sergipe. E-mail: reneasalm@,gmail.com. ORCID: https://orcid.org/0000-0002-9288$\underline{0740}$

$\overline{2}$ Doutor em Linguística pela Universidade Federal de Minas Gerais. Docente da Faculdade de Letras da Universidade Federal de Alagoas. E-mail: alanjardel@,gmail.com. ORCID: http://orcid.org/0000-0002-0438$\underline{1352}$
} 
Volume 16 - Número 1 - jan/jul de 2021

e baseando-se em dados reais e não em intuições, como propunham estruturalistas e gerativistas.

Nesse sentido, o objeto de estudo que se apresenta para a sociolinguística é o vernáculo, ou seja, a fala menos monitorada. A esse respeito, Labov (2008 [1972], p. 244) apresenta o problema de como conseguir que as pessoas falem o vernáculo sabendo que estão sendo gravadas. O autor afirma que o problema não é insolúvel e apresenta algumas soluções para minimizar a questão que ele denomina "paradoxo do observador".

A metodologia quantitativa proposta por Labov (1972) de uma sociolinguística variacionista, em que a língua é considerada heterogênea, passível de variações, foi fundamental para sistematizar algo que varia constantemente de acordo com fatores que não podem ser controlados pelo pesquisador. Tais variações linguísticas podem ocorrer devido a fatores linguísticos, mas também a condicionantes externos à língua (extralinguísticos) tais como sexo, idade, classe social e escolaridade.

A sociolinguística variacionista aborda a variabilidade e mutabilidade como fenômenos característicos de todas as línguas naturais. Fatores linguísticos e sociais estão intimamente relacionados nesses processos variáveis sincrônicos que ocorrem constantemente na nossa fala e podem provocar mudanças no nosso sistema linguístico.

Em uma comunidade de fala, há formas diferentes de dizer a mesma coisa com o mesmo valor de verdade: são as "variantes linguísticas" cujo conjunto consiste na "variável linguística" (TARALLO, 2006, p. 8). Na comunidade de fala, as variantes linguísticas podem coexistir ou entrarem em conflito quando se estabelece a mudança em progresso. Quando uma variante "supera" a outra, a variação se consolida e ocorre a mudança linguística.

A variação que estamos estudando se refere à preposição para, que, além desta forma, se apresenta ainda sob outras formas com o mesmo valor de verdade em suas variantes pra e $p a$. Embora o processo de variação para $>p r a>p a$ seja de ocorrência notória, há ainda poucos estudos que analisaram tal fenômeno (FELGUEIRAS, 1993; LUCENA, 2001; SILVA, 2010, por exemplo).

Embasados na teoria da linguística variacionista laboviana, cujo objeto de estudo é a estrutura e a evolução da língua em seu contexto real de uso que é formado pela comunidade linguística (LABOV, 2008 [1972]); pretendemos: i) verificar qual é a variante mais utilizada pelos falantes de Maceió: para, pra ou pa; ii) identificar a frequência de cada uma delas; iii) observar a influência de fatores linguísticos e extralinguísticos nesse processo de variação, traçando o perfil linguístico dos maceioenses no que se refere ao uso dessas variantes. Para tanto, realizamos gravações de áudio que foram anotadas no aplicativo ELAN (HELLWIG e GEERTS, 2013) e para a análise quantitativa multivariacional dos dados utilizamos o Goldvarb X (SANKOFF, TAGLIAMONTE e SMITH, 2005).

A nossa pesquisa mostra-se relevante devido a um número ainda pequeno de estudos variacionistas que tratem da variação da preposição para. Tanto quanto sabemos, não há, até o presente momento, nenhum trabalho feito para o português falado em Maceió sobre a preposição para e suas variantes na perspectiva da sociolinguística variacionista, como nos propomos a desenvolver.

\section{Entendendo o(s) fenômeno(s)}

A língua apresenta frequentemente muitas variedades devido ao seu caráter heterogêneo. É comum que certas formas sejam mais prestigiosas e outras mais socialmente estigmatizadas. No caso da preposição a que nos propusemos a estudar, a forma para é forma padrão, preconizada pelas gramáticas tradicionais (CUNHA e CINTRA, 2008; CEGALLA, 2008; ROCHA LIMA, 2008) como ideal. É possível que tal forma seja também considerada 
Volume 16 - Número 1 - jan/jul de 2021

mais prestigiosa, enquanto que as demais variantes ( $p r a$ e $p a$ ), não previstas nas gramáticas normativas, sejam menos prestigiosas ou estigmatizadas.

Algumas gramáticas (BECHARA, 2010; PERINI, 2010; BAGNO, 2011) já admitem o uso da variante pra como uma contração que acontece na fala devido à junção da preposição com outras palavras. Castilho (2010, p. 595) apresenta apenas um exemplo do uso da variante pra, ao abordar as classes de verbos que selecionam preposições, mas não faz nenhum comentário a respeito. Apesar de algumas dessas obras serem intituladas "do português brasileiro", a forma mais inovadora $p a$ ainda não é abordada, ainda que pesquisas prévias (XAVIER, 2013; SILVA, 2010; SANTOS, 2004; LUCENA, 2001) já tenham demonstrado que tal variante está presente na fala dos brasileiros.

Esse processo de redução variável da preposição para (para $>$ pra $>$ pa) é explicada pela supressão de fonemas no interior da palavra, nesse caso, ocorrendo dois processos. No primeiro, a variante pra é resultado da queda do fonema /a/, que provoca a supressão de uma sílaba na preposição (para > pra), ou seja, ocorre a síncope da vogal central / a /. Silva (2011, p. 203) afirma que síncope é o "fenômeno fonológico caracterizado pela omissão de uma vogal e que ocasiona a redução de uma sílaba da palavra. Por exemplo, a palavra xícara tem três sílabas, e a forma com síncope, ou seja, xícra, tem duas sílabas". A esse respeito, Bagno (2013, p. 108) afirma que esse "encolhimento" acontece em determinadas palavras "para caberem no ritmo natural do $\mathrm{PNP}^{3}$, que é um ritmo paroxítono, no qual a sílaba tônica é sempre a penúltima".

A redução no número de sílabas altera também a estrutura silábica da preposição para, que é consoante/vogal (CV), para consoante/consoante/vogal (CCV) na sua variante pra. Entretanto, de acordo com Holm (1992, apud NARO e SCHERRE, 2007, p. 121), "há evidência na estrutura silábica do português brasileiro popular de que ele surgiu de uma variedade previamente crioulizada do português que tinha uma forma canônica de $\mathrm{CV}$, uma consoante e uma vogal". Isso talvez explique o processo de variação $(p r a>p a)$, o surgimento da forma inovadora $p a$, de modo a retomar a estrutura silábica canônica do português popular brasileiro.

A definição de Silva (2011) para o fenômeno da síncope não explicaria o outro processo pra > pa, uma vez que há o cancelamento da tepe / / / e não de uma vogal. Além disso, não há redução no número de sílabas. A esse processo a autora denomina apagamento, que é o "fenômeno fonológico em que um segmento consonantal ou vocálico é cancelado [...] $\mathrm{O}$ apagamento de consoantes ocorre, tipicamente, nas bordas das palavras ou em encontros consonantais" (SILVA, 2011, p. 59-60). No caso do processo pra $>$ pa, ocorre o apagamento do / / / em encontro consonantal.

Já para Silva (2010, p. 19) "entre as formas não padrão PRA e PA ocorre uma síncope da vibrante $/ \mathrm{r} /$, transformando a estrutura silábica, ou seja, retorna o padrão silábico sem perda de sílabas". Também coaduna com essa afirmação Xavier (2013, p. 39), ao asseverar que a "síncope geralmente ocorre em sílabas postônicas de palavras proparoxítonas e essa redução dos proparoxítonos no dialeto pode causar o apagamento de consoantes". Nesse sentido, a autora mostra exemplos de supressão não apenas de vogais, mas também de consoantes como um processo de síncope, encontrados em sua pesquisa, tais como, pássaro/passo e bêbado/bebo.

Entendemos o fenômeno de variação em estudo, para $>$ pra $>$ pa, embasados nos conceitos abordados por Silva (2011) e Holm (1992), ou seja, o primeiro processo refere-se ao fenômeno da síncope da vogal /a/ reduzindo o número de sílabas e alterando a estrutura silábica padrão do português falado no Brasil, enquanto que no segundo processo há o apagamento da consoante / $\mathrm{f}$, de modo a retornar ao padrão CV de estrutura silábica.

${ }^{3}$ PNP (português não-padrão). 
Volume 16 - Número 1 - jan/jul de 2021

\subsection{Estudos prévios}

Algumas pesquisas foram desenvolvidas no português brasileiro analisando fenômenos de síncope e apagamento de consoantes em encontros consonantais. Entretanto, poucos enfocaram a variação que ora analisamos e menos ainda seguiram a metodologia da sociolinguística laboviana. Ao abordar características linguísticas de falares rurais goianos, por exemplo, Santos (2004), seguindo uma metodologia qualitativa, incluiu a redução da preposição para a pa como característica de um enunciado típico da fala rural, como em: “... pidi paia $p a$ fazê ota casa"; “... tudo $p a$ grória de Deus".

Outro estudo (não variacionista) foi o de Xavier (2013), que analisou as variações linguísticas existentes em uma turma da primeira série do ensino médio de um colégio estadual de Goiás, comparando-as com as variações presentes no livro didático utilizado. A autora identificou que a preposição para foi pronunciada de três formas diferentes nas falas dos estudantes e que as variantes $/ \mathrm{pra} / \mathrm{e} / \mathrm{pa} /$ foram utilizadas por todos os falantes, inclusive realizando junções da preposição com artigos, como, por exemplo, /pos/ resultante de $/ \mathrm{pa} /+$ /os/, e /prum/ resultante de /pra/ + /um/.

Felgueiras (1993), Lucena (2001) e Silva (2010) desenvolveram pesquisas utilizando o método quantitativo da sociolinguística laboviana, ao estudarem a variação da preposição para. Felgueiras (1993) utiliza dados do Programa de Estudos do Uso da Língua (PEUL) a fim de analisar as variações da preposição para no Rio de Janeiro. Já Lucena (2001) estudou a variação da preposição para na fala da Paraíba, utilizando o corpus VALPB (Variação Linguística da Paraíba). Silva (2010) analisou dados do corpus VALTINS (Variação Linguística do Tocantins), enfocando nativos do município de Araguatins.

Silva (2010) comparou os seus resultados com os encontrados por Lucena (2001), uma vez que as metodologias adotadas foram semelhantes, e encontrou similaridades e dissimilaridades. Com relação à ocorrência das variantes, por exemplo, a autora verificou que a variante pra foi a mais utilizada (54\%) pelos falantes do seu corpus em relação a pa (45\%), enquanto o autor verificou maior ocorrência da variante pa $(49 \%)$ em relação a pra $(45 \%)$. Em ambas as pesquisas, houve um percentual muito baixo de ocorrência da variante para.

A variável social escolaridade também foi confrontada por Silva (2010) no que se refere à variante inovadora $p a$. Tal comparação evidenciou que a forma $p a$ é estigmatizada de acordo com os pesos relativos encontrados nos dois trabalhos. Já a variável sexo mostrou resultados divergentes entre as pesquisas. No trabalho de Lucena (2001), os indivíduos do sexo feminino realizaram mais a forma estigmatizada $p a$ enquanto que os resultados apresentados por Silva (2010) mostram uma maior realização desta variante por indivíduos do sexo masculino.

\subsection{Variáveis dependentes e independentes}

A metodologia proposta pela sociolinguística variacionista possibilita, por meio de métodos quantitativos, sistematizar as correlações entre a variação linguística em estudo (considerada variável dependente) e fatores internos (linguísticos) e/ou externos (sociais) que atuam como condicionadores do fenômeno dessa variação (considerados variáveis independentes).

[...] um dado fenômeno linguístico variável é influenciado por variáveis dependentes (grupo de itens que estabelecemos como regra variável) e independentes (grupos de fatores condicionadores - linguísticos e extralinguísticos -, pelos quais se buscam explicações para as escolhas dos falantes). (FREITAG e LIMA, 2010, p. 79). 
A variável linguística dependente em estudo é a preposição para em suas variantes [para], [pra] e [pa]. Pesquisas anteriores elencaram alguns fatores internos e externos à língua que poderiam influenciar essa variável dependente. Felgueiras (1993), por exemplo, destacou o forte efeito que a variável linguística independente do paralelismo linguístico exerce sobre a alternância das variantes [para], [pra] e [pa] no plano discursivo.

Além do paralelismo, Silva (2010) considerou como fatores linguísticos que condicionariam a redução variável da preposição para a presença da tepe na primeira ou segunda sílaba do item seguinte e o contexto fonológico seguinte, ou seja, vogais ou consoantes no início da palavra seguinte. A autora classificou as vogais em anteriores, central e posteriores; e as consoantes em labial, coronal e dorsal. Quanto aos fatores extralinguísticos, ela considerou três variáveis: sexo, anos de escolarização e faixa etária. Em seus resultados, a autora identificou que a variável paralelismo se mostrou irrelevante para a ocorrência da variação, contradizendo os achados de Felgueiras (1993) para o dialeto carioca.

A pesquisa de Lucena (2001) também analisou a interferência de variáveis independentes linguísticas e sociais na variação da preposição para. O autor considerou o contexto fonológico seguinte e a presença de tepe no segmento seguinte como fatores internos ao sistema linguístico e o sexo e a escolaridade como fatores sociais, que afetam o processo de variação.

Além dessas variáveis linguísticas apontadas pelos autores como possíveis condicionadores ao processo de variação em análise nos dialetos que pesquisaram, consideramos ainda o acento da sílaba seguinte e a classe do segmento seguinte como variáveis que afetam o fenômeno da variação (para $>$ pra $>$ pa) abordado em nossa pesquisa, cujo método explicitamos a seguir.

\section{Procedimentos metodológicos}

O corpus desse estudo se constituiu de trinta entrevistas, uma média de quinze minutos de gravação cada, com informantes da cidade de Maceió - AL. Esta pesquisa integra o projeto "Variação Linguística no Português Alagoano - PORTAL" (Aprovado pelo Comitê de Ética da Universidade Federal de Alagoas, parecer $n^{\circ}$ 621.763) e os dados analisados fazem parte da amostra inicial do projeto, coletados no primeiro semestre de 2014. As entrevistas basearamse em diálogos e narrativas sobre experiências pessoais de cada informante, de modo a envolvê-los emocionalmente na tentativa de capturar maior espontaneidade possível.

Ser natural de Maceió e não ter vivido mais de um ano fora da cidade foram os critérios que observamos para selecionar os informantes. Fatores como classe social e escolaridade não foram considerados para esta análise, uma vez que nosso corpus não foi coletado com tais informações. O corpus de 30 informantes foi estratificado por sexo e idade, conforme ilustrado no Quadro 1.

Quadro 1: Estratificação do corpus

\begin{tabular}{|c|c|c|}
\hline Informantes & Masculino & Feminino \\
\hline Jovem $(18-30$ anos $)$ & 5 & 5 \\
\hline Adulto $(40-55$ anos $)$ & 5 & 5 \\
\hline Idoso $(>65$ anos $)$ & 5 & 5 \\
\hline
\end{tabular}

Fonte: elaborado pelos autores 
Volume 16 - Número 1 - jan/jul de 2021

Neste trabalho, as gravações de áudio foram anotadas no Programa ELAN (HELLWIG e GEERTS, 2013) e utilizamos o programa estatístico Goldvarb X (SANKOFF, TAGLIAMONTE e SMITH, 2005) para a análise quantitativa multivariacional dos dados.

\subsection{Variáveis em estudo}

A variável linguística dependente em estudo é a preposição para em suas variantes [para], [pra] e [pa], variações que estariam condicionadas por variáveis independentes linguísticas como o tepe no item seguinte, o paralelismo, o contexto fonológico seguinte, o acento e a classe do item seguinte; e extralinguísticas, tais como o sexo e a idade.

A variável sexo é considerada como um dos fatores que condicionam a variação linguística (CHAMBERS e SCHILLING, 2013). Para Labov (2008 [1972], p. 281), "as mulheres usam menos formas estigmatizadas do que os homens e são mais sensíveis do que os homens ao padrão de prestígio". Baseando-se nesse pressuposto e em resultados mostrados em pesquisas anteriores, partimos da hipótese de que há uma tendência do sexo masculino a usar mais a forma inovadora do que o sexo feminino.

Com relação à faixa etária, Labov (2008 [1972]) mostra que falantes mais jovens apresentam uma tendência a usar a forma inovadora com mais frequência do que os mais velhos que favoreceriam a forma padrão. Tal hipótese já foi comprovada em outras pesquisas sociolinguísticas e a testamos também em nosso corpus em relação ao uso das variantes [para], [pra] e [pa]. Para isso, dividimos os nossos informantes em três faixas etárias, conforme já mostrado no Quadro 1.

Além desses fatores extralinguísticos, outros de natureza linguística também foram definidos para o estudo da variação da preposição para, como a presença de tepe no segmento seguinte. Nesse sentido, partimos da hipótese de que haveria uma tendência maior ao uso da variante [pa] se a palavra seguinte apresentasse um tepe, ou seja, evitaríamos pronunciar tepes em palavras consecutivas. Para tanto, verificamos a presença de tepe na primeira sílaba, como em (1); na segunda sílaba (2) e; a ausência de tepe na palavra seguinte (3):

(1) “... saio pa trabalhar cedo..." (PMI)

(2) “... eu falo pa caramba..." (SMA)

(3) “... voltar pra casa..." (BMI)

Outra variável linguística considerada foi a do paralelismo, partindo da hipótese de que haveria uma tendência das variantes serem influenciadas pela forma precedente de mesma natureza. Por exemplo, ao enunciarmos a forma [pra], existiria uma tendência a repeti-la em seguida, como podemos verificar em (4):

(4) “... levava uma cartinha pra brincar, mas pra correr isso eu não fazia...” (RFJ)

Quanto ao contexto fonológico seguinte, observamos a presença de consoantes e vogais seguindo a proposta de Silva (2010), que classificou as consoantes em labiais (bilabiais e labiodentais), coronais (dentais, alveolares, alveopalatais e palatais) e dorsais (velares e uvulares); e as vogais em anterior, central e posterior. A hipótese levantada para esta variável é a de que haveria uma tendência à repetição de sons de natureza articulatória semelhante, ou seja, as consoantes labiais e a vogal central em contexto seguinte à preposição em estudo seriam mais favorecedoras à ocorrência da variante [pa].

Analisamos ainda se a sílaba imediatamente posterior à preposição era acentuada ou não e de que forma isso poderia interferir na variação estudada. Partimos da hipótese de que, considerando o princípio de alternância rítmica, haveria uma tendência ao favorecimento da variante [para], caso a sílaba seguinte fosse acentuada, como em (5), e das variantes [pra] e [pa], caso não houvesse acento na sílaba seguinte, como em (6):

(5) “... não vejo muita saída para essa situação...” (NFJ)

(6) “... eu vou ficar calado pra manter amizade..." (MMJ) 
Volume 16 - Número 1 - jan/jul de 2021

Além desses, outro fator de natureza linguística que verificamos nesse estudo foi a classe da palavra seguinte à preposição. Para tanto, não consideramos a classificação morfológica tradicional, pois teríamos uma diferença muito significativa no número de ocorrências de umas em relação a outras, além de certamente haver uma flutuação estatística nos resultados ao utilizar muitos fatores. Por essas razões decidimos agrupá-las em palavras de classe aberta e palavras de classe fechada. Conforme classificação de Ilari et al. (2014, p. 10), seriam palavras de classes abertas "substantivo, verbo, adjetivo, advérbio" e de classes fechadas "pronome, especificador, preposição, conjunção". Obviamente que, ao considerar tal classificação, também atentamos para as análises que os autores trazem na obra, salientando que essa classificação não é tão rígida a esse respeito, uma vez que depende também de aspectos semânticos.

\section{Análise dos dados}

Do corpus analisado, verificamos que, das setecentas e vinte ocorrências, apenas seis foram da variante para, o que representa menos de $1 \%$ do universo de ocorrências. Devido a esse número inexpressivo, a variante para foi retirada da análise estatística. O Quadro 2 evidencia a frequência de cada variante.

Quadro 2: Número de ocorrências de cada variante investigada
\begin{tabular}{|c|c|c|}
\hline Variantes & Frequência & $\%$ \\
\hline Para & 6 & 0,8 \\
\hline $\mathrm{Pra}$ & 416 & 57,8 \\
\hline $\mathrm{Pa}$ & 298 & 41,4 \\
\hline Total & 720 & 100 \\
\hline
\end{tabular}
Fonte: elaborado pelos autores

A partir do Quadro 2, podemos constatar que, no português falado em Maceió-AL, há uma maior probabilidade de uso das variantes [pra] e [pa] em relação à variante [para]. Tal variante provavelmente deve limitar-se, no português, a variedades escritas. Diante desses dados, é possível notar a preferência pelo uso da variante pra na fala dos maceioenses.

Nossa pesquisa então passa a enfocar a variação $(p r a>p a)$ da preposição para, considerando os fatores já descritos na metodologia.

Após analisarmos os dados utilizando o Goldvarb, verificamos que as variáveis paralelismo e classe da palavra seguinte não apresentam significância estatística para o processo (significância $=0,18$ e 0,13 , respectivamente). Dessa forma, não foi possível comprovar a hipótese levantada acerca desses fatores. As demais variáveis independentes selecionadas nesse estudo mostraram-se estatisticamente significativas para o processo de apagamento do / $/$ na variação $p r a>p a$ (significância $<0,001)$.

Com relação à variável faixa etária como condicionante de variação linguística, Tarallo (2006, p. 65) afirma que pode haver "a relação de estabilidade das variantes", caso não exista correlação entre a variável dependente e a faixa etária, ou, ainda, pode ocorrer uma situação de mudança linguística em progresso quando "o uso da variante mais inovadora for mais frequente entre os jovens, decrescendo em relação à idade dos outros informantes". A Tabela 1 mostra a relação entre a variável dependente $p a$ e a faixa etária no nosso corpus. 
Volume 16 - Número 1 - jan/jul de 2021

Tabela 1: Tabela de contingência para a variável dependente pa e a variável independente faixa etária

\begin{tabular}{ccccc}
\hline $\begin{array}{c}\text { Variável } \\
\text { Independente }\end{array}$ & Aplicação & N total & $\%$ & Peso Relativo \\
\hline Jovens & 62 & 210 & 29.5 & .34 \\
\hline Adultos & 102 & 240 & 42.5 & .54 \\
\hline Idosos & 134 & 264 & 50.8 & .60 \\
\hline
\end{tabular}

Significância $<0,001$

Fonte: elaborada pelos autores

Os resultados da Tabela 1 demonstram que os jovens estão apagando menos (.34) do que os adultos (.54) e do que os idosos (.60). Ou seja, os mais jovens (entre 18 e 30 anos) utilizaram mais a variante [pra] (.66). O resultado indica um processo de mudança linguística em direção à variante mais conservadora. Outros estudos se fazem necessários para que tal resultado seja investigado mais profundamente. Neste estudo, não controlamos a variável escolaridade. $\mathrm{O}$ fato dos mais jovens utilizarem menos a variante inovadora pode estar relacionado ao fato de que indivíduos dessa faixa etária estão mais sujeitos às interferências escolares que buscam propagar variedades mais prestigiadas socialmente. Interessante destacar que, na idade entre 40 e 55 anos, o uso da forma inovadora aumentou (.54) e, após os 65 anos, os maceioenses falaram mais ainda a variante pa (.60), conforme demonstrado no Gráfico 1.

Gráfico 1: Efeito da variável dependente pa

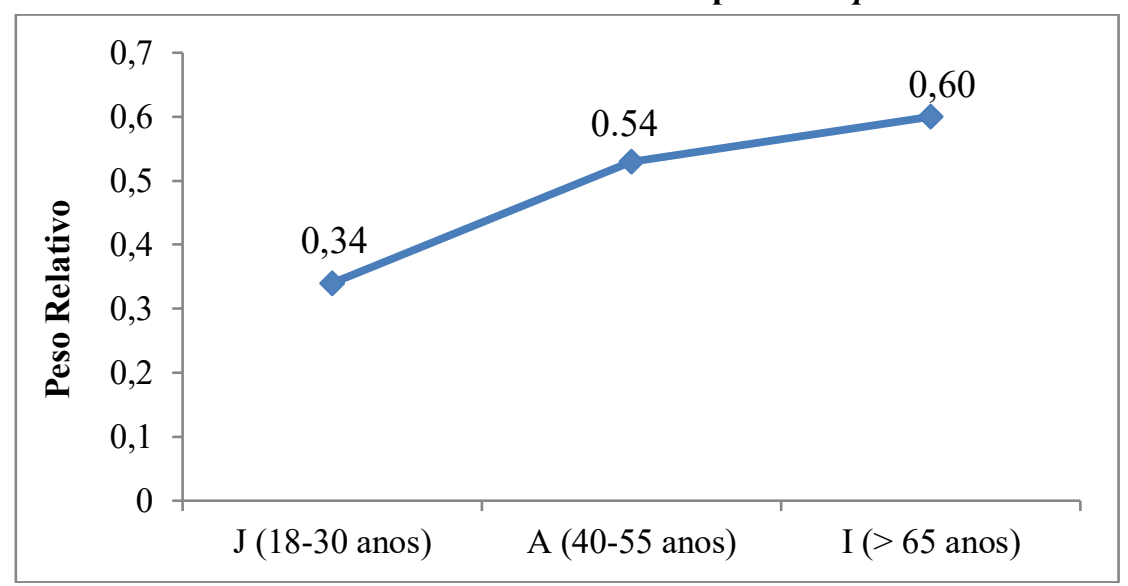

Significância $<0,001$

Fonte: elaborado pelos autores

Nesse sentido, não poderíamos afirmar que se trata de uma mudança linguística em curso, uma vez que a forma mais utilizada pelos jovens não é a forma inovadora e sim a mais conservadora, o que contraria a nossa hipótese e resultados de outras pesquisas de que falantes mais jovens apresentariam uma tendência a usar a forma inovadora com mais frequência do que os mais velhos, que favoreceriam a forma mais conservadora.

Também não poderíamos afirmar que seria um processo de variação estável porque os informantes adultos não diminuíram o uso da forma mais conservadora em relação aos jovens. Tal variável provavelmente careça de um corpus ampliado para se chegar a conclusões mais precisas. Os nossos achados divergem um pouco dos de Silva (2010), que verificou um processo de variação estável no corpus de Araguatins - TO.

Para o fator social sexo, considerando a hipótese de que há uma tendência do feminino usar menos as formas socialmente estigmatizadas, nossa hipótese é a de que a forma $p a$ seria 
Volume 16 - Número 1 - jan/jul de 2021

menos utilizada pelas mulheres, o que também foi constatado em Silva (2010) e Lucena (2001). Tal hipótese foi confirmada conforme demonstrado na Tabela 2, em que evidenciamos, como resultado do corpus coletado, que os falantes do sexo masculino nativos da cidade de Maceió falam mais a forma inovadora $p a(.60)$ do que os falantes do sexo feminino (.42).

Tabela 2: Tabela de contingência para a variável dependente pa e a variável independente sexo

\begin{tabular}{ccccc}
\hline $\begin{array}{c}\text { Variável } \\
\text { Independente }\end{array}$ & Aplicação & $\mathrm{N}$ total & $\%$ & Peso Relativo \\
\hline Feminino & 133 & 390 & 34.1 & .42 \\
\hline Masculino & 165 & 324 & 50.9 & .60 \\
\hline
\end{tabular}

Significância $<0,001$

Fonte: elaborada pelos autores

A Tabela 3 mostra resultados que confirmam parcialmente a nossa hipótese de que evitamos falar tepes em palavras consecutivas, uma vez que encontramos como bastante favorecedor do apagamento do /r/ na preposição quando há tepe na primeira sílaba da palavra seguinte (.91), embora o mesmo pareça não acontecer quando o tepe aparece na segunda sílaba (.33), o que indica que a presença de tepe na segunda sílaba da palavra seguinte favorece a ocorrência da forma pra (.67). A ausência de tepe parece não ter apresentado muita relevância nesse processo de variação (.48). Então, nos parece que os maceioenses evitam pronunciar tepes em sílabas consecutivas e não necessariamente em palavras consecutivas.

Tabela 3: Tabela de contingência para a variável dependente pa e a variável independente tepe na palavra seguinte

\begin{tabular}{ccccc}
\hline $\begin{array}{c}\text { Variável } \\
\text { Independente }\end{array}$ & Aplicação & N total & $\%$ & Peso Relativo \\
\hline Ausência de tepe & 258 & 632 & 40.8 & .48 \\
\hline $\begin{array}{c}\text { Tepe na primeira } \\
\text { sílaba }\end{array}$ & 27 & 33 & 81.8 & .91 \\
\hline $\begin{array}{c}\text { Tepe na segunda } \\
\text { sílaba }\end{array}$ & 13 & 49 & 26.5 & .33 \\
\hline
\end{tabular}

Significância $<0,001$

Fonte: elaborada pelos autores

Com relação a essa variável linguística, nossos resultados se aproximam dos de Silva (2010) e Lucena (2001), que verificaram como favorável à ocorrência da variante [pa] a presença de tepe na palavra seguinte. Entretanto, a autora identificou que a presença de um tepe na segunda sílaba também favoreceria a ocorrência da forma mais inovadora, enquanto que nossos resultados mostram o contrário.

Tabela 4: Tabela de contingência para a variável dependente pa e a variável independente contexto fonológico seguinte

\begin{tabular}{ccccc}
\hline $\begin{array}{c}\text { Variável } \\
\text { Independente }\end{array}$ & Aplicação & N total & $\%$ & Peso Relativo \\
\hline Consoante coronal & 73 & 154 & 47.4 & .61 \\
\hline Consoante labial & 76 & 214 & 35.5 & .41 \\
\hline
\end{tabular}


Volume 16 - Número 1 - jan/jul de 2021

\begin{tabular}{ccccc}
\hline Consoante dorsal & 12 & 56 & 21.4 & .35 \\
\hline Vogal anterior & 25 & 74 & 33.8 & .42 \\
\hline Vogal central & 44 & 103 & 42.7 & .48 \\
\hline Vogal posterior & 68 & 113 & 60.2 & .67 \\
\hline
\end{tabular}

Significância $<0,001$

Fonte: elaborada pelos autores

Quanto ao contexto fonológico seguinte, levantamos a hipótese de que as consoantes labiais e a vogal central em contexto seguinte à preposição em estudo seriam mais favorecedoras à ocorrência da variante [pa], que foi confirmada pela pesquisa de Silva (2010). No entanto, nossos resultados (Tabela 4) não confirmam essa hipótese já que o contexto seguinte favorecedor da variante [pa] são a vogal posterior (.67) e a consoante coronal (.61). Corrobora com os nossos achados a pesquisa de Lucena (2001) para a variante de João Pessoa - PB, em que verificou pesos relativos de (.61) para consoantes coronais e (.54) para vogais posteriores como contextos favorecedores da ocorrência de $p a$.

Tabela 5: Tabela de contingência para a variável dependente pa e a variável independente acento na sílaba seguinte

\begin{tabular}{ccccc}
\hline $\begin{array}{c}\text { Variável } \\
\text { Independente }\end{array}$ & Aplicação & N total & $\%$ & Peso Relativo \\
\hline Com acento & 59 & 203 & 29.1 & .36 \\
\hline Sem acento & 239 & 511 & 46.8 & .56 \\
\hline
\end{tabular}

Significância $<0,001$

Fonte: elaborada pelos autores

A hipótese que levantamos para a variável acento na sílaba seguinte foi de que haveria uma tendência ao favorecimento da variante [para], caso a sílaba seguinte fosse acentuada, e das variantes [pra] e [pa], caso não houvesse acento na sílaba seguinte, já que são monossílabos que apresentam uma determinada acentuação, então em seguida não haveria acento (Princípio da alternância rítmica). A variante [para] foi descartada da análise devido ao número inexpressivo de ocorrências (menos de 1\%), mas mesmo assim não descartamos a variável acento e curiosamente ela parece afetar o processo de variação em estudo ( $p r a>p a$ ), como é possível perceber na Tabela 5. Os resultados nos apresentam um favorecimento maior à ocorrência de $p a$ quando a sílaba seguinte não é acentuada (.56), enquanto a presença de acento na sílaba seguinte parece favorecer a ocorrência de pra (.64).

\section{Conclusão}

Nesse estudo, enfocamos o processo de variação da preposição para em suas variantes [para], [pra] e [pa] na fala de nativos da cidade de Maceió, embasados na sociolinguística variacionista laboviana, uma vez que estabelecemos como condicionantes desse processo de variação algumas variáveis linguísticas e extralinguísticas.

Após a realização da coleta de dados por meio das gravações, realizamos a anotação no aplicativo ELAN (HELLWIG e GEERTS, 2013) e verificamos o número de ocorrências de cada variante. Ao identificar a inexpressividade da frequência da variante [para] em nosso 
Volume 16 - Número 1 - jan/jul de 2021

corpus (menos de 1\%), realizamos a rodada binária pra x pa no Goldvarb, considerando como conservadora a forma pra e como inovadora a forma $p a$.

Dentre os fatores que analisamos, foram favoráveis à ocorrência da forma inovadora $p a$ : i) as consoantes coronais e as vogais posteriores, o que refuta a hipótese que levantamos e os achados de Silva (2010) para a variante de Araguatins - TO, em que verificou as consoantes labiais e a vogal central como favorecedoras da variante [pa]; ii) a presença de tepe na primeira sílaba da palavra seguinte, o que confirma parcialmente a nossa hipótese de que evitamos falar tepes em palavras consecutivas, uma vez que, se o tepe aparecer na segunda sílaba do item seguinte, favorece a ocorrência da forma pra, ou seja, parece que os maceioenses evitam pronunciar tepes em sílabas consecutivas; e iii) a ausência de acento na sílaba seguinte, resultado curioso, uma vez que a variante $p a$, apesar de apresentar uma acentuação menos proeminente do que pra devido à presença da vibrante nesta, aquela também possui acento e, portanto, a variável acento não deveria ter interferido no processo de variação após o descarte da forma para que apresenta a última sílaba sem acento.

Quanto às variáveis independentes extralinguísticas, verificamos que os informantes do sexo masculino tendem a falar mais a variante mais inovadora em relação aos do sexo feminino, confirmando a nossa hipótese embasada na literatura prévia. Já com relação à variável faixa etária, nossos resultados contrariam a literatura e também a nossa hipótese, pois identificamos que os informantes idosos tendem mais a produzir a variante [pa] do que os jovens, talvez devido ao fator escolaridade.

Fatores sociais como escolaridade e classe social não foram consideradas nessa análise, uma vez que nosso corpus não foi coletado com tais informações, o que consideramos não invalidar nossos achados, mas sim uma oportunidade para que outros estudos sejam realizados na variante enfocada incluindo tais variáveis.

Diante da inexpressividade no número de ocorrências da variante [para] em nossos resultados, bem como nos de Silva (2010) e Lucena (2001) para outras variedades do português falado no Brasil, podemos concluir ainda que tais resultados sinalizam para uma hipótese levantada por Menon (2014), de que esta forma não existe na fala dos brasileiros, mas sim na escrita; e que as ocorrências na fala de tal variante decorre da interferência da escrita na fala, conforme apontado por Silva (2010), ao afirmar que os falantes que produziram a forma para são pessoas mais escolarizadas.

\section{Referências}

BAGNO, Marcos. A Língua de Eulália: novela sociolinguística. 17.ed. São Paulo: Contexto, 2013.

BAGNO, Marcos. Gramática pedagógica do português brasileiro. São Paulo: Parábola Editorial, 2011.

BECHARA, Evanildo. Gramática escolar da língua portuguesa. 2.ed. Rio de Janeiro: Nova Fronteira, 2010.

CASTILHO, Ataliba T. de. Nova gramática do português brasileiro. São Paulo: Contexto, 2010.

CEGALLA, Domingos Paschoal. Novíssima gramática da língua portuguesa. 48.ed. São Paulo: Companhia Editora Nacional, 2008.

CHAMBERS, J. K.; SCHILLING, N. The Handbook of Language Variation and Change. 2.ed. London: Wiley-Blackwell, 2013.

CUNHA, Celso; CINTRA, Luís F. Lindley. Nova gramática do português contemporâneo. 5.ed. Rio de Janeiro: Lexicon, 2008. 
Volume 16 - Número 1 - jan/jul de 2021

FELGUEIRAS, Carmen Maria. Análise da variação no uso da preposição PARA. Dissertação (Mestrado) - Programa de Pós-graduação em Linguística. Rio de Janeiro: Universidade Federal do Rio de Janeiro, 1993.

FREITAG, Raquel Meister Ko; LIMA, Geralda de Oliveira Santos. Sociolinguística. São Cristóvão: CESAD-UFS, 2010. Disponível em: <https://www.sigaa.ufs.br/sigaa/verProducao? idProducao $=51300 \&$ key $=13 \mathrm{~b} 5245328 \mathrm{~d} 6 \mathrm{f} 8 \mathrm{dbb} 8 \mathrm{~b} 4 \mathrm{~d} 1 \mathrm{~b} 2016 \mathrm{e} 68 \mathrm{c} 4>$. Acesso em: $15 \mathrm{abr} .2018$. HELLWIG, B.; GEERTS, J. ELAN - Linguistic Annotator. Versão 5.0. Disponível em: $<$ https://www.mpi.nl/corpus/html/elan/index.html $>$. Acesso em: 11 de setembro de 2018.

ILARI, Rodolfo (Org.). Gramática do português culto falado no Brasil. São Paulo: Contexto, 2014.

LABOV, William. Padrões Sociolinguísticos. Trad.: M. Bagno, M. M. P. Scherre, C. R. Cardoso. São Paulo: Parábola, 2008 [1972].

LUCENA, Rubens Marques de. Comportamento sociolinguístico da preposição PARA na fala da Paraíba. Dissertação (Mestrado) - Programa de Pós-graduação em Linguística. João Pessoa: Universidade Federal da Paraíba, 2001.

MENON, Odete Pereira da Silva. PARA: uma história de variação ou de gramaticalização? In: XXIX ENANPOLL. Florianópolis, 2014.

NARO, Anthony Julius; SCHERRE, Maria Marta Pereira. Origens do português brasileiro. São Paulo: Parábola Editorial, 2007.

PERINI, Mário Alberto. Gramática do português brasileiro. São Paulo: Parábola Editorial, 2010.

ROCHA LIMA, Carlos Henrique da. Gramática normativa da língua portuguesa. 47.ed. Rio de Janeiro: José Olympio, 2008.

SANKOFF, David; TAGLIAMONTE, Sali A.; SMITH, Eric (2005). Goldvarb X: A variable rule application for Macintosh and Windows. Department of Linguistics, University of Toronto. Disponível em: $<$ http://individual.utoronto.ca/tagliamonte/goldvarb. html>. Acesso em: 30 jun. 2019.

SANTOS, Tânia Ferreira Rezende. Falares rurais brasileiros. Revista da UFG, n. 1, v. 7, jun. 2004. Disponível em: <http://www.proec.ufg.br/revista_ufg/agro/R26_rurais.html >. Acesso em: 22 abr. 2018.

SILVA, Nahete de Alcantara. A preposição para e suas variantes no falar araguatinense. Dissertação (Mestrado) - Programa de Pós-graduação em Linguística. João Pessoa: Universidade Federal da Paraíba, 2010.

SILVA, Thaís Cristófaro. Dicionário de Fonética e Fonologia. São Paulo: Contexto, 2011. TARALlO, Fernando. A Pesquisa Sociolinguística. 7.ed. São Paulo: Ática, 2006.

XAVIER, Elizabeth Gomes. O livro didático e as variações linguísticas no ensino da língua portuguesa na $1^{a}$ série do ensino médio do colégio estadual Vale da Esperança Formosa - GO. Monografia (Licenciatura) - Licenciatura em Educação do Campo. Planaltina: Universidade de Brasília, 2013. 